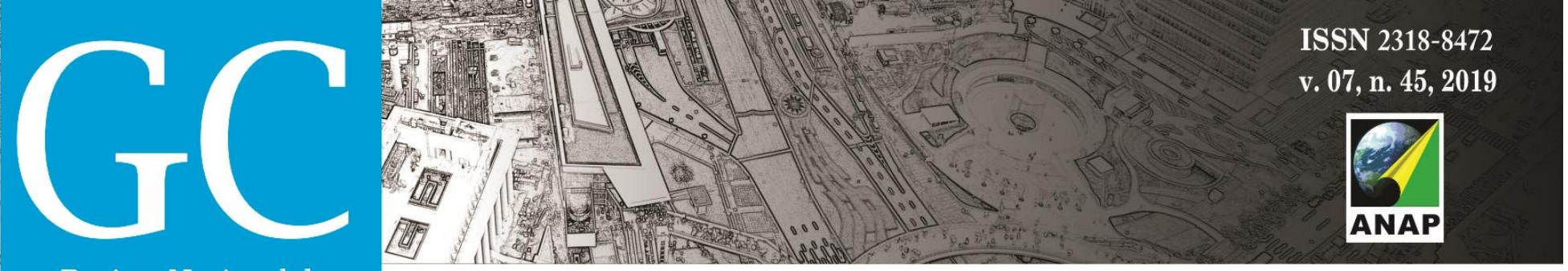

Revista Nacional de

Gerenciamento de Cidades

\title{
Diagnóstico da qualidade espacial no Asilo Colônia Aimorés
}

Spatial quality diagnosis in the Cologne Asylum Aimorés

Diagnóstico de la calidad espacial en el Asilo Colonia Aimorés

Tatiana R. Jacon Gebara Universidade Estadual Paulista “Julio de Mesquita Filho" (UNESP-PPGARQ)

Renata Cardoso Magagnin Universidade Estadual Paulista “Julio de Mesquita Filho" (UNESP-PPGARQ) 


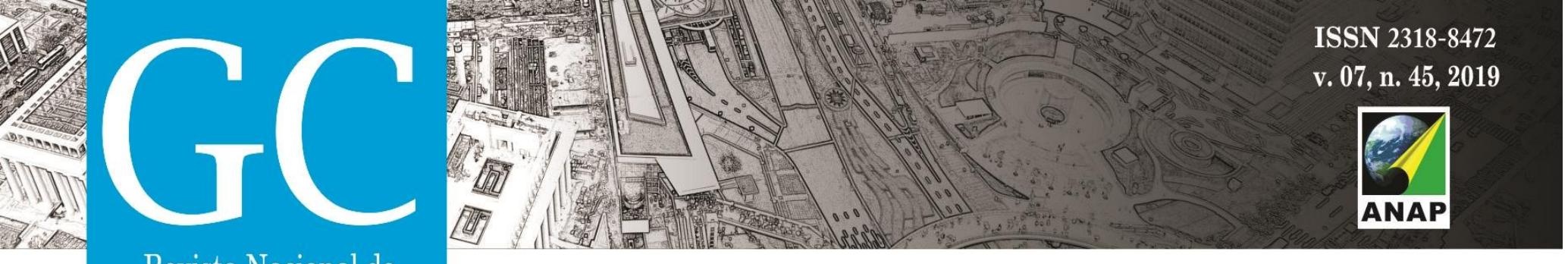

\section{Revista Nacional de \\ Gerenciamento de Cidades}

\section{RESUMO}

Atualmente, muitos asilos-colônias brasileiros ainda estão em funcionamento. Abrigam antigos pacientes, instituições de pesquisas e permitem visitações externas. Podem ser considerados locais de interesse turístico. No entanto, por serem áreas tombadas pelo patrimônio histórico, e por não sofrerem manutenção adequada, podem não oferecer qualidade espacial e segurança para seus frequentadores. Diante desse contexto, esse artigo apresenta o resultado uma pesquisa que avaliou a qualidade espacial na área tombada do asilo colônia Aimorés (Bauru - SP). A metodologia foi composta por técnicas de observação (passeio guiado ou walkthrough e mapa comportamental). A partir dos resultados obtidos, pode-se afirmar que a utilização das duas técnicas foi essencial para entender, a partir de uma visão técnica, como a qualidade espacial pode interferir no uso do espaço. A partir dos resultados obtidos, os gestores da área podem intervir a partir de ações mais imediatistas ou a longo prazo, para melhorar a qualidade espacial desse local.

PALAVRAS-CHAVE: Centro histórico. Qualidade Espacial. Mapa Comportamental. Walkthrough.

\section{ABSTRACT}

Currently, many asylum-colonies are still in operation. They house old patients, research institutions and external experiences. They can be places of tourist interest. However, these areas are listed by historical patrimony, are not protected, can not be dispatched with quality and safety to their patrons. In this context, this article has the result of a research that evaluated a spatial quality in the area of asbestos colony Aimorés (Bauru - SP). The methodology was done with observation techniques (guided walk or step by step and behavioral map). From the obtained results, it can be affirmed that the use of both techniques was essential for the understanding, from a technical technique, as a space technique can interfere in the use of the space. From the results obtained, the managers of the area can intervene from more immediate or long term phrases, to improve the quality of the place.

KEYWORDS: Historic center. Spatial Quality. Behavioral Map. Walkthrough.

\section{RESUMEN}

Actualmente, muchas asilo-colonias brasileñas todavía están en funcionamiento. Abrigan a antiguos pacientes, instituciones de investigación y permiten visitas externas. Pueden considerarse lugares de interés turístico. Sin embargo, por ser áreas tumbadas por el patrimonio histórico, y por no sufrir mantenimiento adecuado, pueden no ofrecer calidad espacial y seguridad para sus asistentes. En este contexto, este artículo presenta el resultado una investigación que evaluó la calidad espacial en el área tumbada del asilo colonia Aimorés (Bauru - SP). La metodología fue compuesta por técnicas de observación (paseo guiado o walkthrough y mapa conductual). A partir de los resultados obtenidos, se puede afirmar que la utilización de las dos técnicas fue esencial para entender, a partir de una visión técnica, cómo la calidad espacial puede interferir en el uso del espacio. A partir de los resultados obtenidos, los gestores del área pueden intervenir a partir de acciones más inmediatas o a largo plazo, para mejorar la calidad espacial de ese local.

PALABRAS CLAVE: Centro histórico. Calidad Espacial. Mapa Comportamental. Walkthrough. 


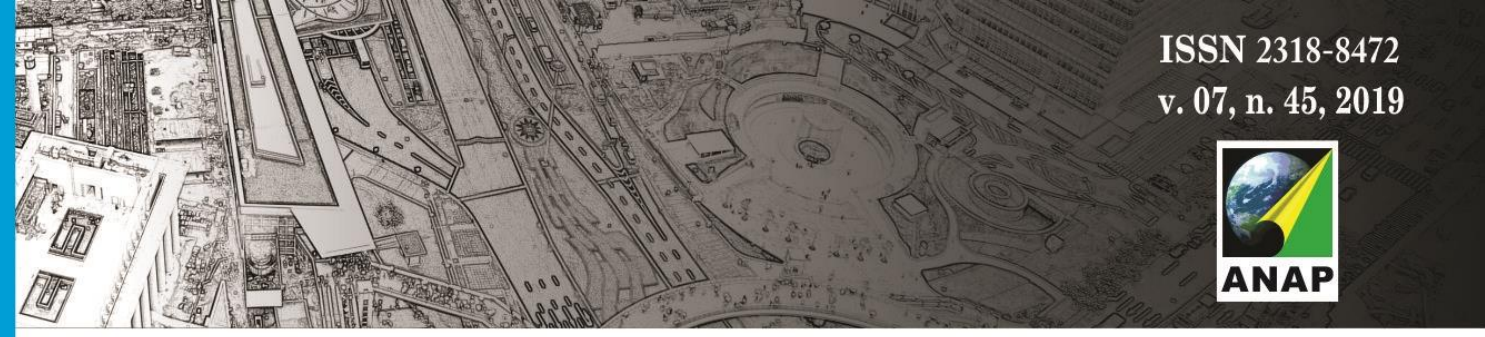

Revista Nacional de

Gerenciamento de Cidades

\section{INTRODUÇÃo}

Os sítios históricos e os espaços de preservação histórico-culturais são ambientes que possuem importante valor histórico-cultural, pois representam um determinado período da história de um lugar. Sua preservação é gerida por leis específicas que asseguram sua permanência para futuras gerações (RIBEIRO, 2008; RIBEIRO; MARTINS; MONTEIRO, 2012).

No entanto, ao observar áreas urbanas tombadas pelo patrimônio histórico, verifica-se que ainda existem locais que não oferecem qualidade espacial e segurança para o deslocamento de pessoas com restrição de mobilidade, sejam idosos ou deficientes físicos. Para que essas pessoas possam usufruir desses espaços é imprescindível que essas áreas sejam adaptadas a todos os cidadãos.

A necessidade em torná-los acessíveis surge como uma oportunidade para a requalificação e transformação local, ao contribuir com a conservação do patrimônio e reassumir seu papel histórico já existente dentro da malha urbana da cidade (MATIAS, 2015).

Atualmente esses locais são protegidos por leis de preservação, que delimitam ou impedem as modificações de suas características históricas, e acarretam em dificuldades para a aplicação, por exemplo, da norma técnica de acessibilidade que garantiria uma maior qualidade espacial a área (GERENTE, 2005).

Diversas pesquisas buscam avaliar a microacessibilidade e a qualidade espacial em áreas urbanas, com diferentes abordagens. Alguns pesquisadores utilizaram técnicas de observação para avaliar o ambiente do pedestre (GERENTE, 2005; RIBEIRO, 2008; PAIVA, 2009; RHEINGANTZ et al., 2009; CUNHA, MATIAS, COSTA, 2012; RIBEIRO; MARTINS; MONTEIRO, 2012; COSTA, 2014; SOUZA, TIBÚRCIO, 2015; CUNHA, GOMES, FERNANDES, 2016; MEDEIROS; MATIAS; COSTA, 2016; LIMA, MAGAGNIN; MOLLES, 2016; GUERRA, 2017; Há um segmento de pesquisadores que analisam espaços públicos tombados pelo patrimônio histórico para identificar os principais problemas enfrentados população em visitas a estes locais (MEDEIROS; MATIAS; COSTA, 2016; PAIVA, 2009; MAGAGNIN; MOLLES, 2016).

De uma maneira geral, essas pesquisas avaliaram áreas centrais tombadas pelo patrimônio histórico, cujo publico alvo eram pessoas com mobilidade reduzida, de diferentes faixas etárias. No entanto, não foi identificada qualquer pesquisa sobre a qualidade espacial em asilos colônias tombados pelo patrimônio histórico.

Os asilos-colônias são locais que abrigam uma importante parte da história do país, por abrigar aquelas pessoas portadoras de hanseníase. Esses locais podem ser denominados de "pequenas cidades", pois possuíam toda a infraestrutura presente em uma cidade, como áreas de moradia, trabalho, atendimento médico, esportes e lazer (igrejas, cassinos, teatros). Esses espaços eram implantados seguindo um programa de zoneamento que subdividia a área do asilo em zonas: sãs, intermediarias e doentes, de acordo com critérios de uso e fluxo para pessoas sãs e doentes.

Atualmente, muitos asilos-colônias brasileiros ainda estão em funcionamento. Abrigam antigos pacientes, instituições de pesquisas sobre hanseníase ou outras doenças, e por terem áreas tombadas pelo patrimônio histórico guardam parte de um importante momento histórico e urbanístico de nosso país. Muitos desses locais permitem visitações externas, são locais de interesse turístico. De acordo com Costa (2014, p. 79) "as estruturas físicas dos asilos colônias precisam ter suas memórias preservadas, pois representam valiosos testemunhos de ações espaciais, resultantes de políticas públicas sanitaristas". Diante do exposto, este artigo 


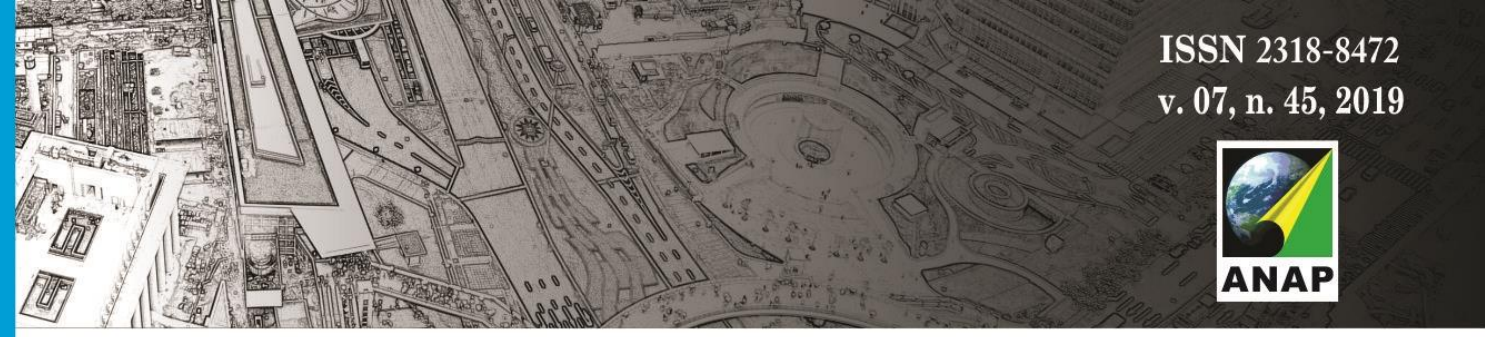

Revista Nacional de

Gerenciamento de Cidades

visa apresentar um diagnóstico e identificar os principais problemas que afetam a qualidade espacial de áreas tombadas pelo patrimônio histórico, como os asilos-colônias, a partir de técnicas de observação. $O$ estudo de caso foi realizado no asilo colônia Aimorés, localizado em Bauru (SP).

\section{PROCEDIMENTOS METODOLÓGICOS}

Para identificar como os usuários utilizam a área tombada do asilo Aimorés e verificar os principais problemas que podem acometer a qualidade espacial foram utilizadas duas técnicas de observação - Passeio Guiado (Walkthrough) e Mapa Comportamental.

\section{- Passeio Guiado (Walkthrough)}

A técnica denominada Passeio Guiado (ou Walkthrough em inglês) pode ser definida como sendo a realização de um percurso dialogado, que utiliza como recursos complementares registros fotográficos e croquis, para o registro das características físicas do espaço que podem influenciar as reações dos participantes durante o percurso (RHEINGANTZ et al., 2009). De acordo com o autor, o Walkthrough é um método que combina simultaneamente observações técnicas com uma entrevista, muito utilizado na avaliação de desempenho do ambiente construído.

Neste artigo foi adotado o seguinte procedimento: i) levantamento da área tombada com o apoio da Diretora técnica de Pesquisa do ILSL - Noêmi Galan, e ii) registro dos dados realizado por meio da planta do local, croquis e registros fotográficos.

A aplicação desta técnica teve por objetivo: i) conhecer os aspectos técnicos ou espaciais da área tombada, e ii) identificar os usos ou funcionalidades dessa área tanto pelo usuário morador quanto visitante (especialistas da área de dermatologia que fazem cursos no ILSL, alunos de escolas da região e público em geral).

Com relação à postura do observador no Passeio Guiado (Walkthrough), foi adotada a abordagem experiencial, cujo pesquisador transmite suas emoções e reações à observação, interagindo com o ambiente. De acordo com esta técnica a observação foi dividida em duas etapas: i) uma observação inicial, para conhecer o espaço e para o reconhecimento inicial dos comportamentos dos usuários; e ii) definição do percurso, observação e coleta de dados. Esta técnica foi aplicada em outubro de 2017.

\section{- Mapa Comportamental}

De acordo com Rheingantz et al. (2009) o mapa comportamental esta técnica de observação permite identificar o comportamento e as atividades dos usuários em um determinado lugar, por meio da identificação de usos, layouts, fluxos e as relações espaciais no local observado. 0 registro das informações (interações, movimentos e a distribuição das pessoas no espaço) e do tempo de permanência em cada ambiente é realizado por meio de gráfico (RHEINGANTZ et al., 2009; CUNHA, MATIAS, COSTA, 2012; SOUZA, TIBÚRCIO, 2015; CUNHA, GOMES, FERNANDES, 2016; LIMA, GUERRA, 2017).

Esta técnica de observação pode ser centrada no lugar ou no espaço e centrada no indivíduo (SOMMER; SOMMER 1997:60-70 apud RHEINGANTZ et a.l, 2009). Nesse artigo foi adotada a observação centrada no 


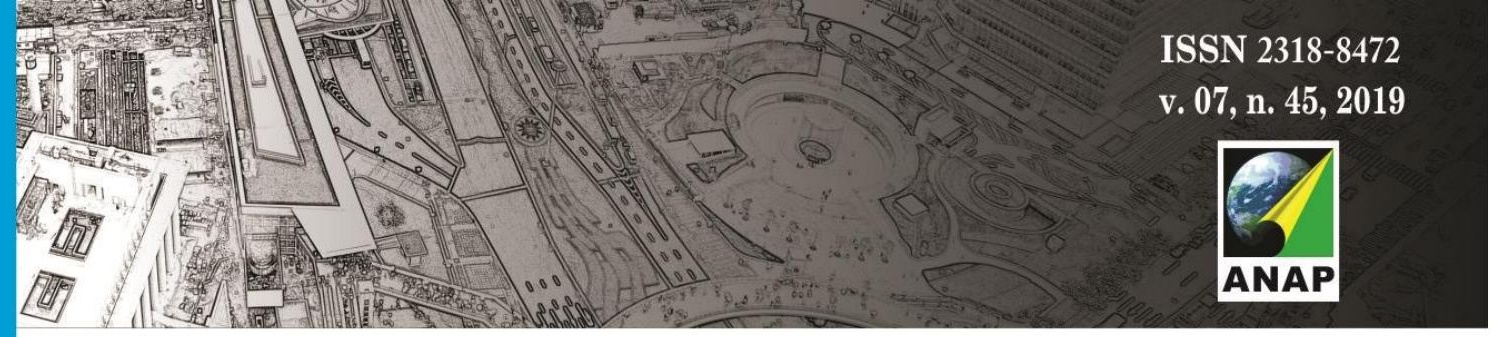

Revista Nacional de

Gerenciamento de Cidades

lugar, ou seja, a pesquisadora ficou parada em um ou mais pontos da área tombada, com boa visibilidade e sem interferência no deslocamento dos usuários.

As observações na área tombada do Instituto Lauro de Souza Lima foram realizadas durante a semana, nos dias 11 de junho (segunda-feira), 13 de junho (quarta-feira) e 14 de junho (quinta-feira), em três horários distintos, início da manhã entre $8 \mathrm{~h}$ e $9 \mathrm{~h}$; final de manhã entre $11 \mathrm{~h}$ e $11 \mathrm{~h} 40$; e fim de tarde entre $17 \mathrm{~h}$ e $18 \mathrm{~h}$, horários já identificados por observação prévia, em que os espaços urbanos são mais utilizados pelos moradores, para desenvolvimento de atividades de lazer.

O objetivo dessas observações foi elaborar um mapa contendo todos os deslocamentos dos moradores na área tombada. A partir da elaboração de um mapa síntese é possível correlacionar esses percursos (aqueles mais utilizados) com os problemas de microacessibilidade (identificados na auditoria técnica), que podem afetar a segurança e o conforto desses moradores, e assim propor diretrizes projetuais para essa área.

\section{ANÁLISE E DISCUSSÃO DOS RESULTADOS}

Nesta seção são apresentadas as duas técnicas de observação na área tombada do Asilo Aimorés, na seguinte sequência: Passeio Guiado (Walkthrough) e Mapa Comportamental.

\section{- Passeio Guiado (Walkthrough)}

O percurso realizado teve inicio no pórtico (entrada principal da área tombada) na Avenida São Carlos (A) em direção aos principais espaços e edifícios: primeira Igreja do Asilo (B), Carville, Museu (antigo Cine Teatro), casas dos moradores (C e D), campo de futebol (E), todo calçamento do entorno (F) e contornou-se a Praça Aimorés, pela Avenida dos Correio da Noroeste, passou em frente a Igreja Nossa Senhora das Dores (G) e finalizou em frente a quadra poliesportiva $(H)$, figura 01 . O percurso escolhido foi definido pela Diretora de Pesquisa do ILSL, Noêmi Galan, e buscou contemplar todo o espaço tombado utilizado por moradores e visitantes. A figura 01 apresenta algumas imagens do percurso. 


\section{Revista Nacional de \\ Gerenciamento de Cidades}

iv) estado de conservação e tipo de piso do sistema viário local que é de paralelepípedo pode comprometer o deslocamento de pedestres nas travessias, pois quando molhado torna-se escorregadio, dificultando assim a locomoção de idosos ou pessoas com algum tipo de deficiência (figura 1, g, j, l, n);

v) estado de conservação e tipo de piso da calçada (pedra portuguesa) encontra-se danificado, e em muitos locais, por falta de manutenção correta, ele não existe o calçamento é apenas de terra o que pode comprometer o deslocamento de qualquer pessoa nesta área, em especial aquelas com restrição de mobilidade (figura $1 \mathrm{c}, \mathrm{e})$;

vi) presença de degraus ou rampas para acesso de alguns edifícios instalados na calçada, e pode atrapalhar a circulação do pedestre. Observa-se em algumas situações o acesso aos edifícios não foram realizados em consonância com as normas de acessibilidade vigentes, por exemplo, a NBR 9050 (figura 1h). 


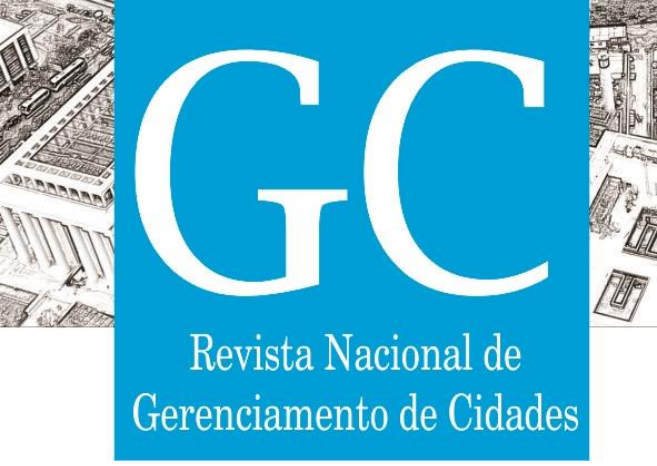

Figura 2 - Mapa síntese dos aspectos técnicos ou espaciais

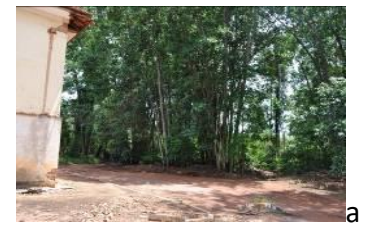

Falta de manutenção no piso

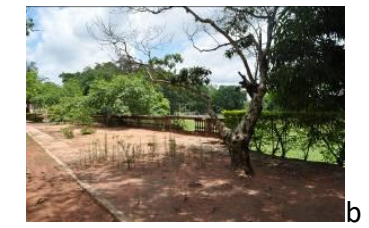

Calçada danificada

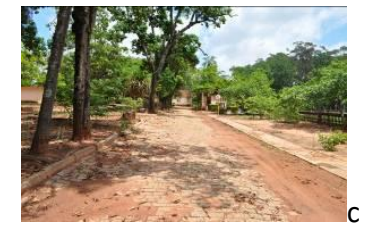

Calçada danificada

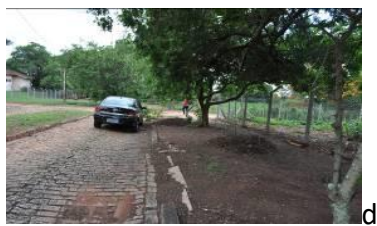

Calçada danificada

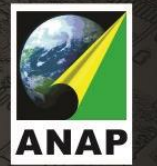

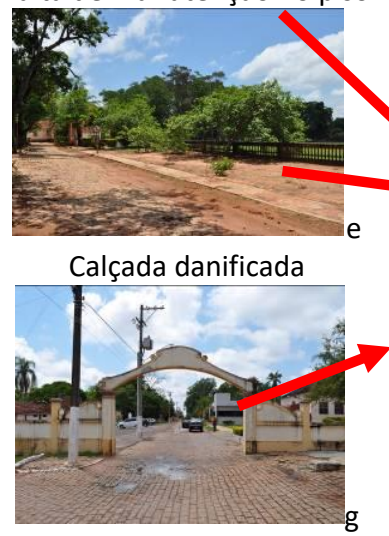

Piso escorregadio

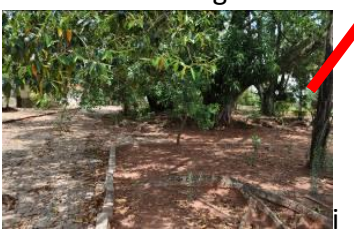

Calçada irregular

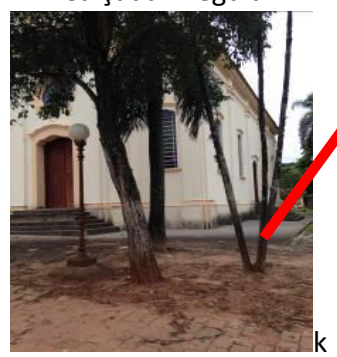

Calçada danificada
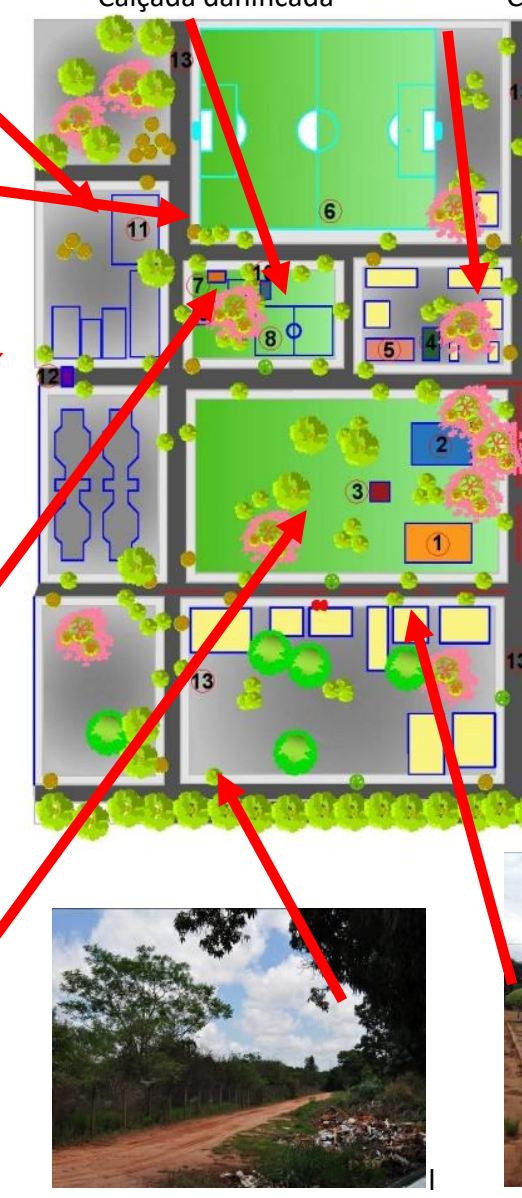

Falta de manutenção no piso

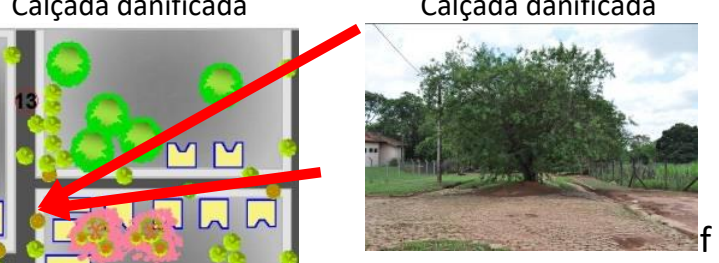

Vegetação irregular
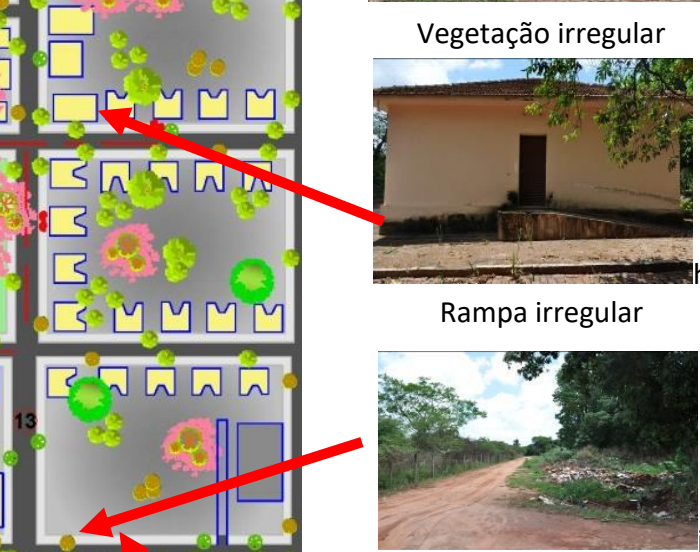

Falta de manutenção no piso

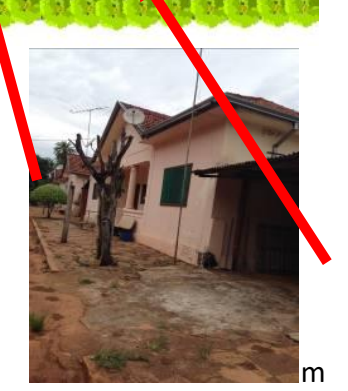

Calçada danificada

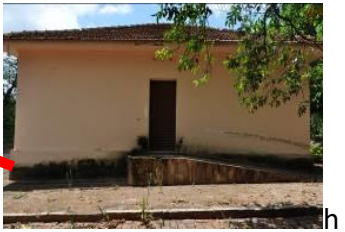

Rampa irregular
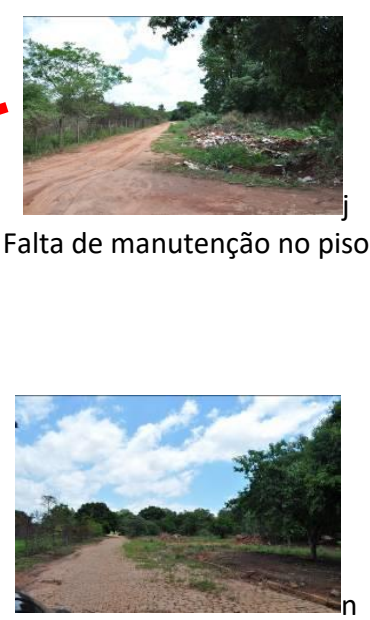

Falta de manutenção no piso

Em relação aos usos de cada espaço ou edifício dessa área tombada observou-se:

i) No geral, os moradores frequentam a Praça Aimorés e todo seu entorno, dificilmente fazem algum tipo de atividade física. Normalmente, se encontram e sentam-se em alguns bancos da praça. Os moradores mantêm a prática de se reunirem em frente a suas casas e conversarem entre eles, sentados em cadeiras ou nos degraus,

ii) Há visitas diárias de pacientes (de todas as faixas etárias), acompanhantes, servidores (adultos e idosos) e ciclistas (adultos). Semanalmente ou quinzenalmente, grupos de estudantes (infantil - de 05-17 anos) e 


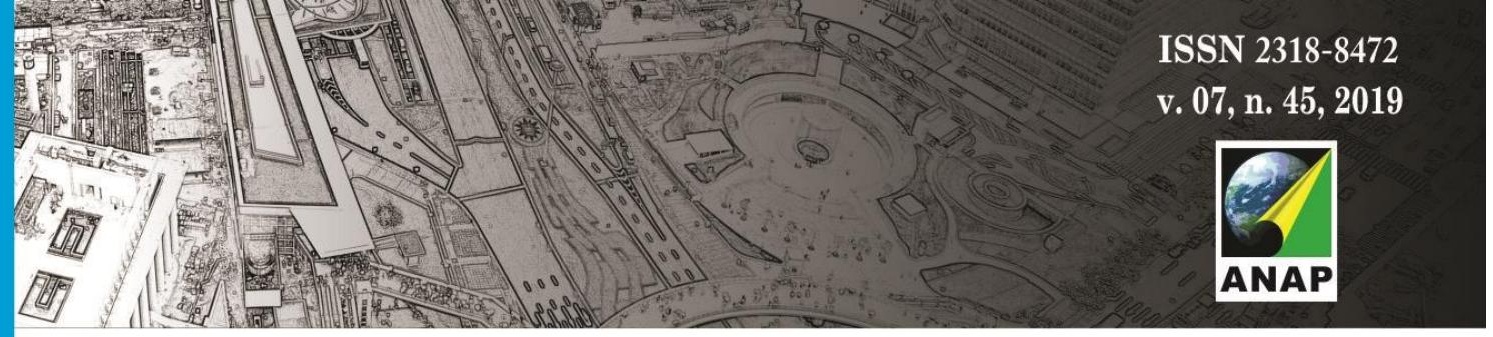

Revista Nacional de

Gerenciamento de Cidades

estudantes de graduação (18 a 28 anos) e mensalmente são oferecido cursos de noções básicas de hansenologia; cursos de prevenção de incapacidades e reabilitação em hanseníase no prédio do Museu (Antigo "Cine Teatro Cassino" (figuras 1, 2). A faixa etária das pessoas que frequentam esses cursos são adultos entre 20 e 50 anos. 0 percurso realizado pelos estudantes é realizado a pé e normalmente o ponto inicial (saída) é realizada na Seção de treinamento e ensino (fora da área tombada), seguindo a Avenida Correio da Noroeste até chegar ao Museu. Além dos visitantes que fazem os cursos esporadicamente, outros locais visitados na área tombada segue a seguinte ordem de frequência: Museu (figura 1, 02), Igreja Nossa Senhora das Dores (figura 1, 01) e Coreto (figura 1, 03), seguindo: Portal (figura 1, 12), Calçamento (figura 1, 13), Quadra Poliesportiva (figura 1, 08), Tablado de dança (figura 1, 09), Bares (Figura 1, 10), Tribuna (figura 1, 07), Campo de futebol (Figura 1, 06), Primeira Igreja do Asilo (Figura 1, 04), Carville (figura 1, 05), Antiga direção e administração (figura 1, 11). Normalmente, quem acompanha esses visitantes são: servidores da Seção de Treinamento e Ensino; servidor do Museu ou assistente social do Instituto Lauro de Souza Lima; ou eventualmente algum museológico estagiário. Ciclistas não são acompanhados. Todo o percurso de visitação é realizado a pé.

iii) Outro local muito utilizado nos finais de semana, para a prática de exercícios físicos de jovens e adultos da comunidade da cidade de Bauru é o campo de futebol. Este local possui boa manutenção, é sombreado e muito agradável para a prática esportiva. $O$ trajeto até a chegada ao campo de futebol tem início no Portal (figura 1, 12), seguindo pelo Tablado de Dança (figura 1, 09), seguindo pelos Bares (figura 1, 10) e finalizando no Campo de futebol, (figura 1,06). Normalmente esse percurso é feito a pé ou de bicicleta. Outra informação relevante, é que por meio de uma empresa privada, é feita a manutenção das calçadas na área tombada do Instituto Lauro de Souza Lima. A reforma mais recente foi feita na Igreja Nossa Senhora das Dores (figura 1, 01) com verba da Secretaria Estadual de Saúde.

\section{- Mapa comportamental}

As observações e as respectivas análises foram analisadas por período, manhã entre $8 \mathrm{~h}$ e $9 \mathrm{~h}$, final de manhã entre $11 \mathrm{~h}$ e $11 \mathrm{~h} 40$, e fim de tarde entre $17 \mathrm{~h}$ e $18 \mathrm{~h}$.

\section{- Período da manhã}

11 de Junho - No primeiro dia de observação, por volta das 9 horas, notou-se uma movimentação em frente ao Carville, sentido a casa dos moradores, localizado atrás da Igreja Nossa Senhora das Dores (legenda número 1, figura 3), duas pessoas se juntaram a um grupo de 3 pessoas e conversavam em pé em frente à uma das casas do asilo (figura 3). 


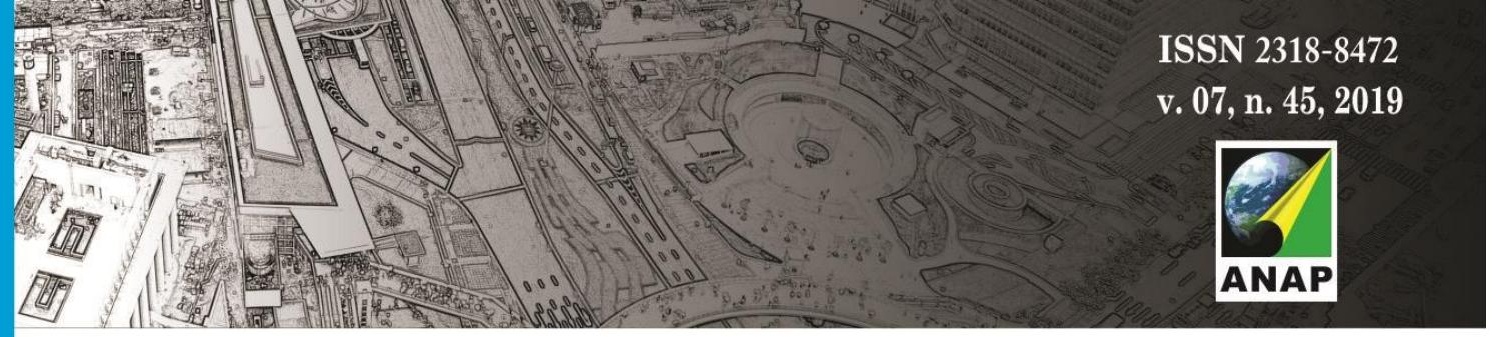

Revista Nacional de

Gerenciamento de Cidades

13 de Junho de 2018 - Durante o segundo dia de observação, às 8h da manhã, foi registrado uma movimentação na entrada e saída de algumas casas, o grupo era composto por 7 pessoas (figura 4). Duas pessoas saem de sua residência na Avenida Correio da Noroeste, e caminham sentido Refeitório. Duas outras pessoas conversam em pé e em frente a uma casa localizada atrás do antigo Cine Teatro (número 2, figura 4) e três pessoas caminham no sentido da casa dos moradores, na via de automóveis.

14 de Junho - no período de observação, por volta das 8h, cinco pessoas caminhavam ao redor da Praça Aimorés (figura 5). Essas pessoas permaneceram por volta de 10 minutos nos arredores da Praça. Três pessoas voltavam do refeitório, sendo que duas, seguiram em direção ao Carville, e as outras duas pessoas, entraram pelo Pórtico (número 12, figura 5) e seguiram a Avenida Correio da Noroeste.

Figura 3 - Mapa comportamental da área tombada do Asilo Aimorés, do dia 11 de junho, período da manhã, sem escala.

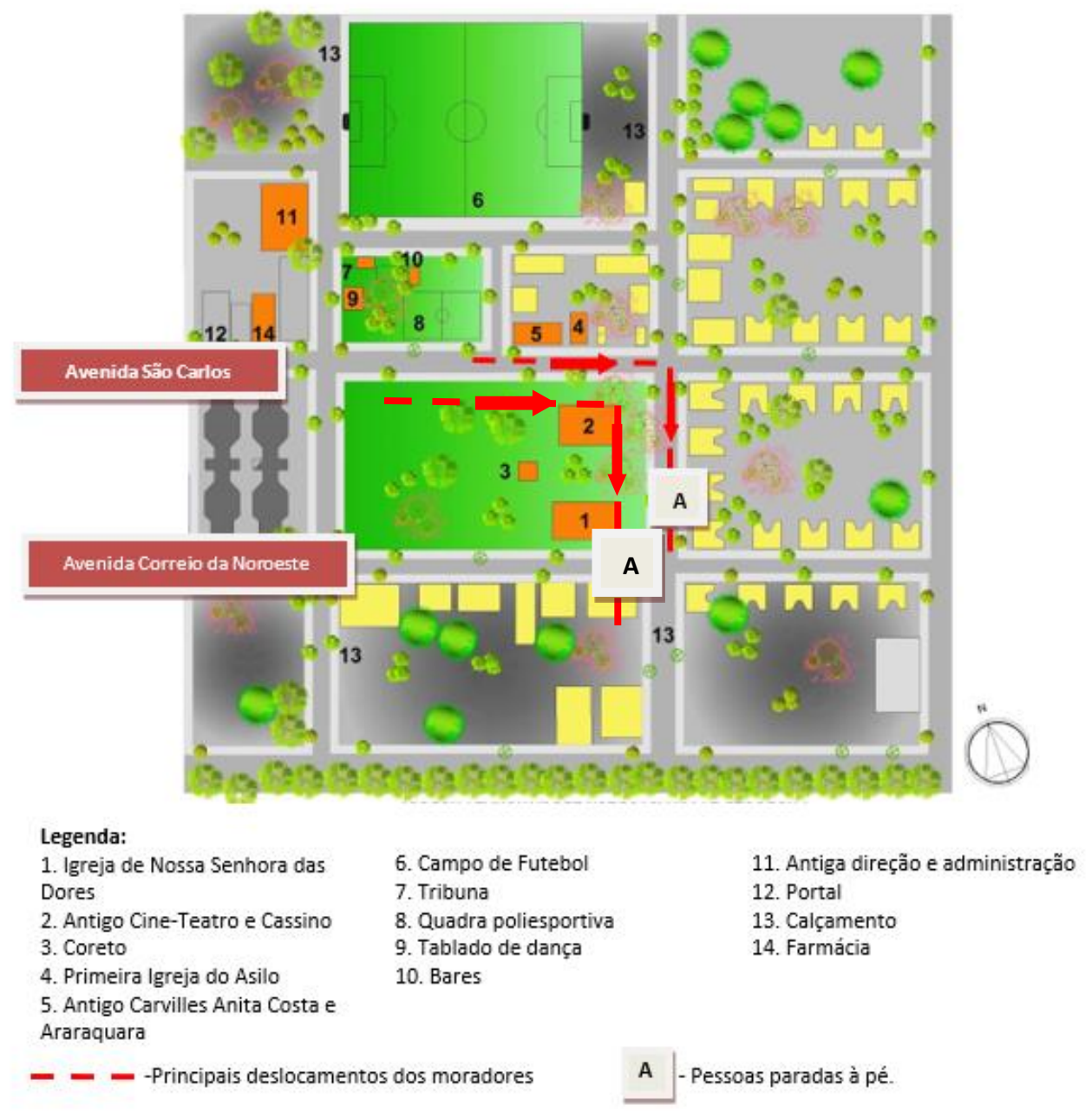




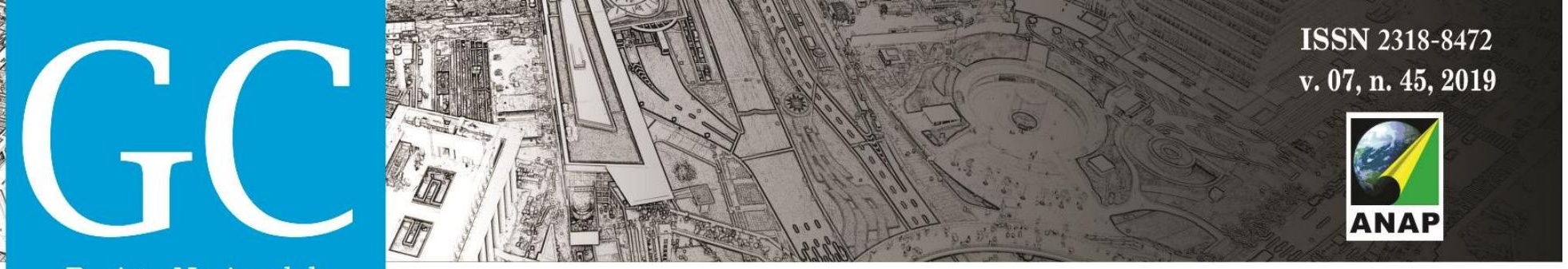

Revista Nacional de

Gerenciamento de Cidades

Figura 4 - Mapa comportamental da área tombada do Asilo Aimorés, do dia 13 de junho, período da manhã, sem escala.

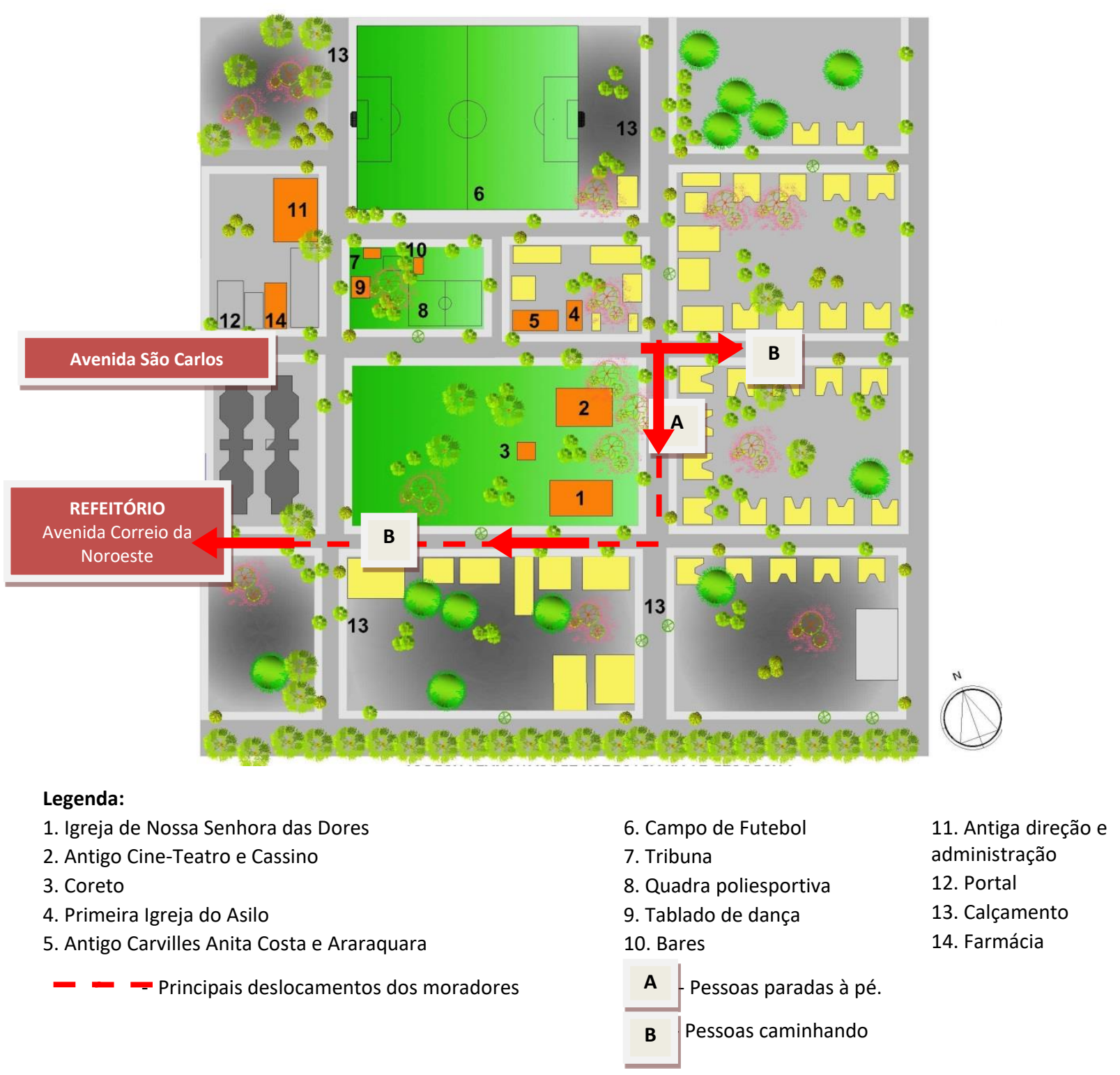




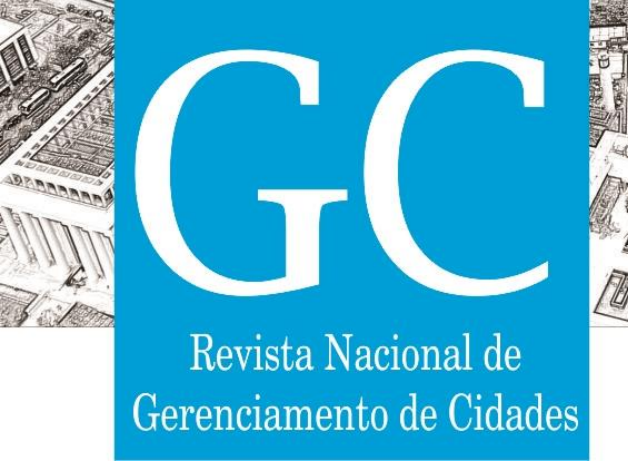

Figura 5 - Mapa comportamental da área tombada do Asilo Aimorés, do dia 14 de junho, período da manhã, sem escala.

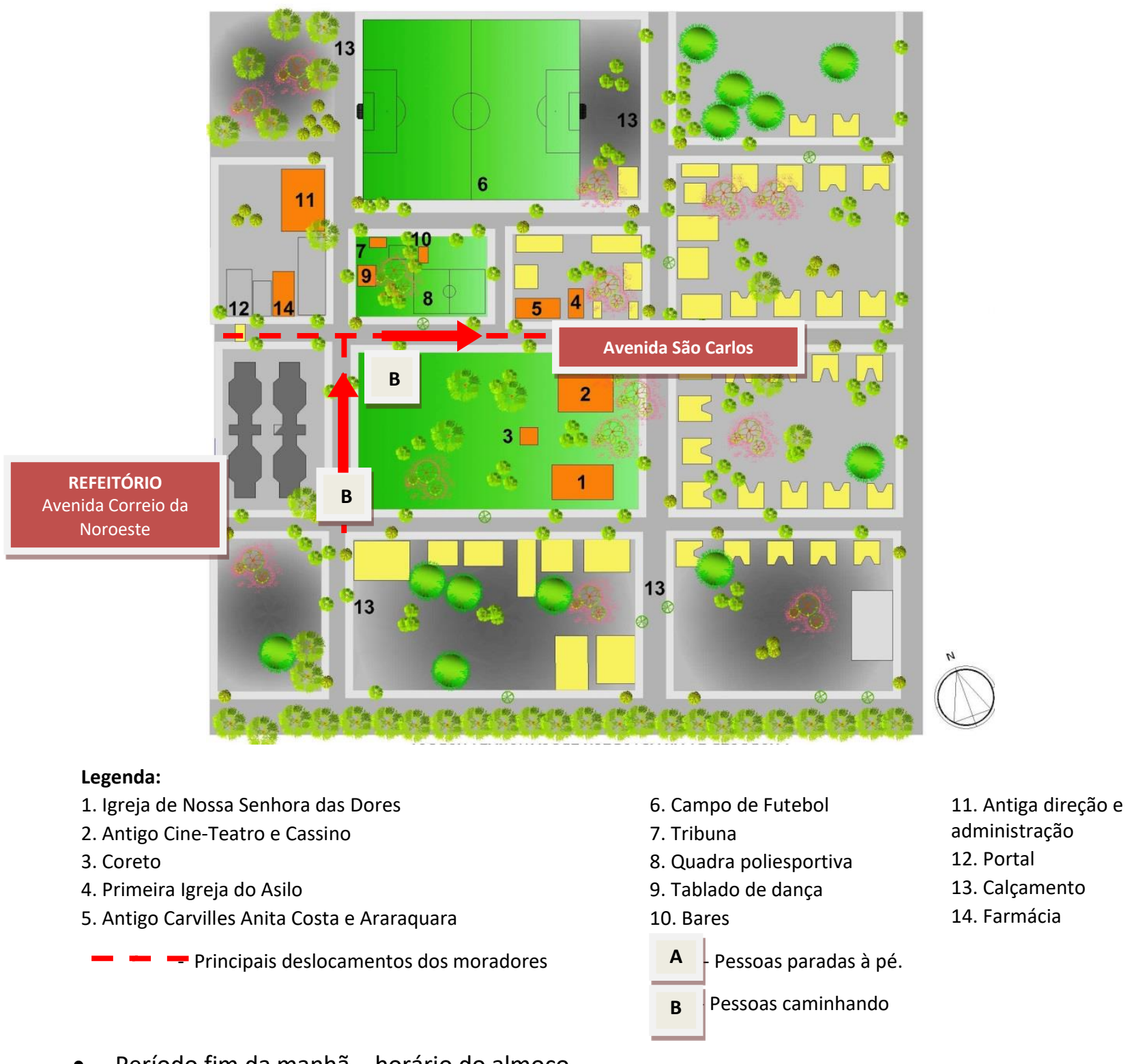

11 de Junho - Por volta das 10h30, três pessoas caminham na praça Aimorés e param e se sentaram rapidamente para conversar nos bancos em concreto, em seguida seguiram juntas para o refeitório - o refeitório abre para receber os moradores nos seguintes horários: das $7 \mathrm{~h}$ até às $8 \mathrm{~h} 30$; das $11 \mathrm{~h}$ às $13 \mathrm{~h}$ e das $17 \mathrm{~h}$ às $18 \mathrm{~h}$ (figura 6 ).

13 de Junho - Por volta das $11 \mathrm{~h} 30$, observou-se que os moradores se conhecem, conversam e caminham em grupos até o refeitório para buscar comida para almoçarem em casa ou para almoçarem juntos no refeitório. 


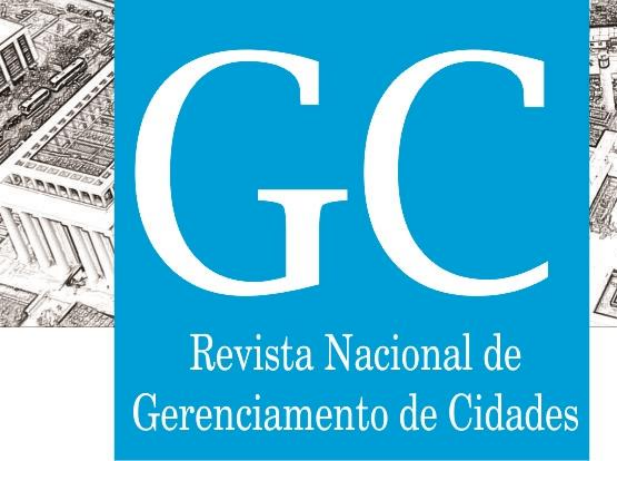

ISSN 2318-8472

O espaço mais utilizado por oito moradores foi: a calçada de contorno da praça Aimorés. Notou-se que seis pessoas estavam em pé e conversando em frente à uma casa (figura 7).

14 de Junho - Próximo ao horário do almoço, por volta das $11 \mathrm{~h}$, foi observada uma movimentação ao redor da praça Aimorés. Nove pessoas caminham, entre elas, duas pessoas se mantêm na via de automóveis (figura 8). O deslocamento foi em sentido ao Refeitório. Os usuários estavam caminhando em grupos de 02 ou 03 pessoas. Não eram pessoas idosas. Aparentemente, eram jovens, que são moradores também do Instituto Lauro de Souza Lima.

Figura 6 - Mapa comportamental da área tombada do Asilo Aimorés, do dia 11 de junho, período fim manhã - horário de almoço, sem escala.

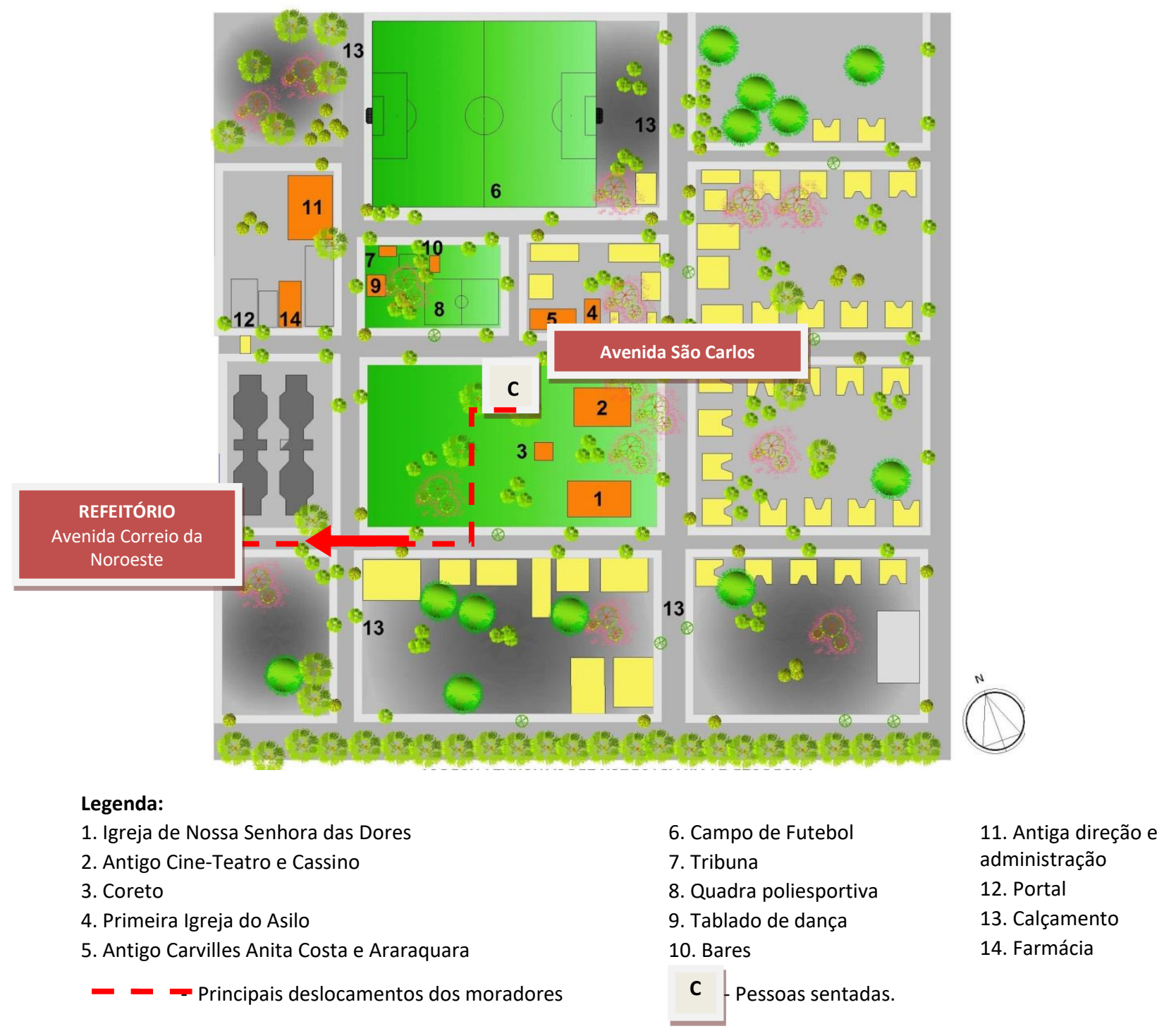




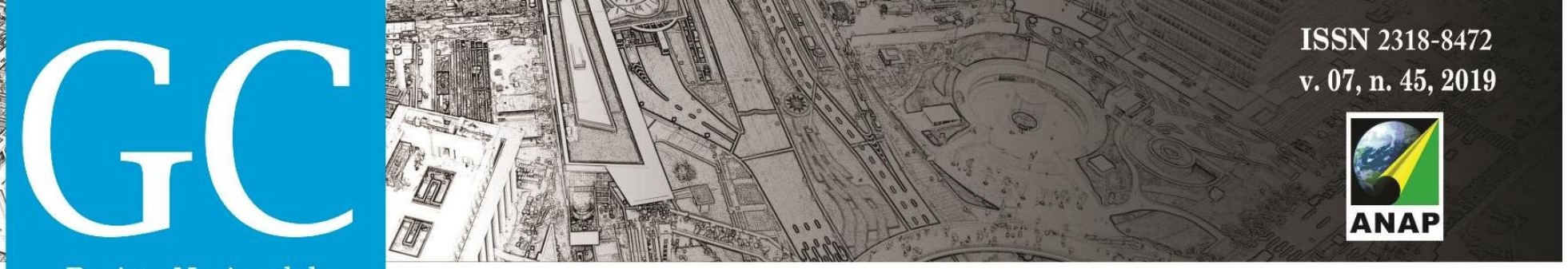

Revista Nacional de

Gerenciamento de Cidades

Figura 7 - Mapa comportamental da área tombada do Asilo Aimorés, do dia 13 de junho, período fim manhã - horário de almoço, sem escala.

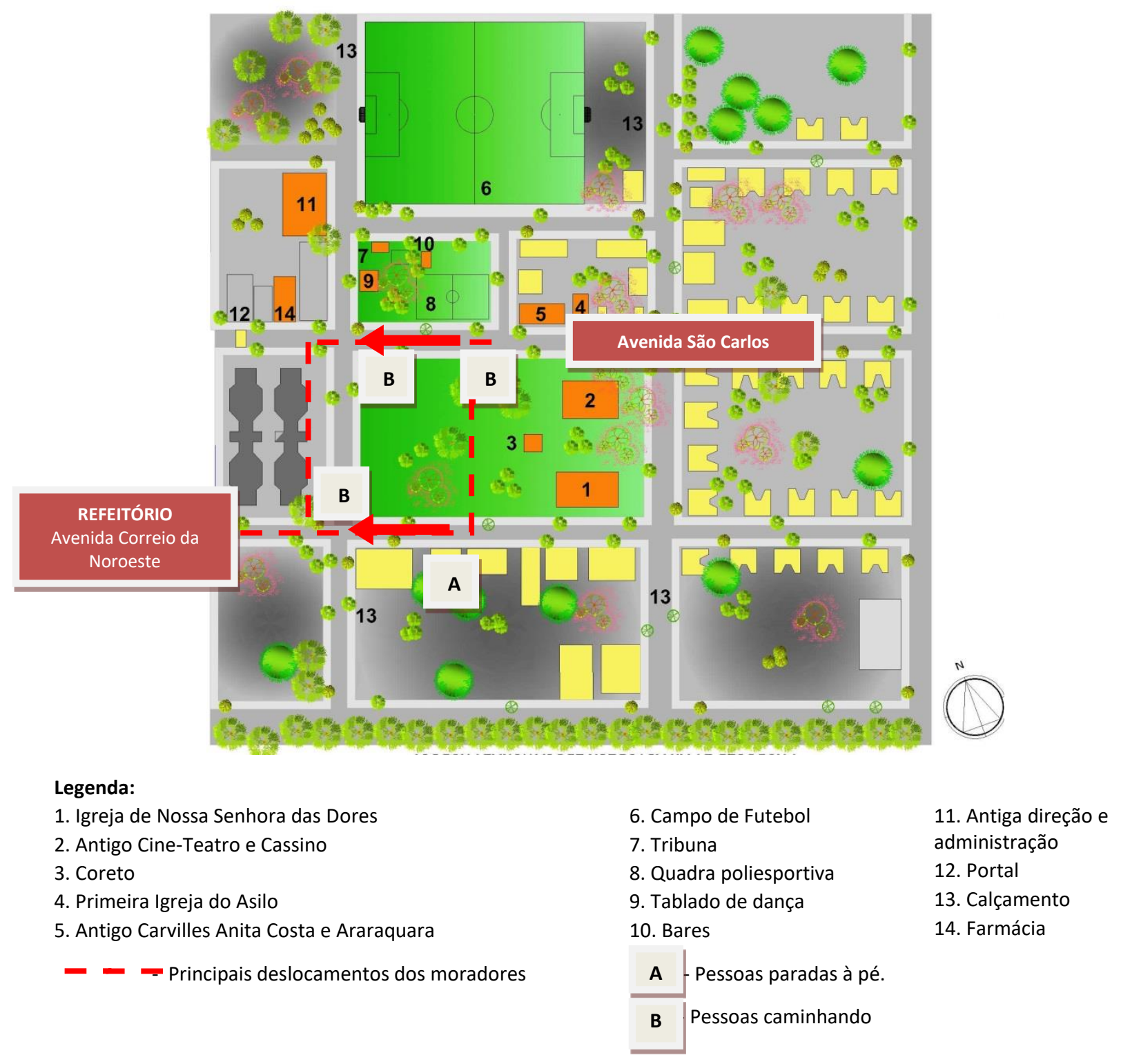




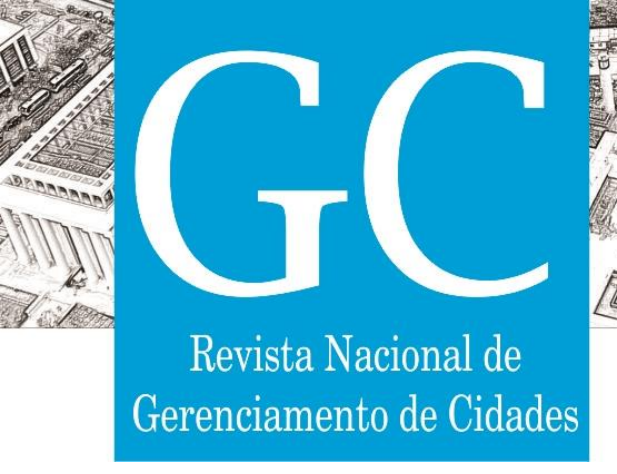

ISSN 2318-8472

Figura 8 - Mapa comportamental da área tombada do Asilo Aimorés, do dia 14 de junho, período fim manhã - horário de almoço, sem escala.

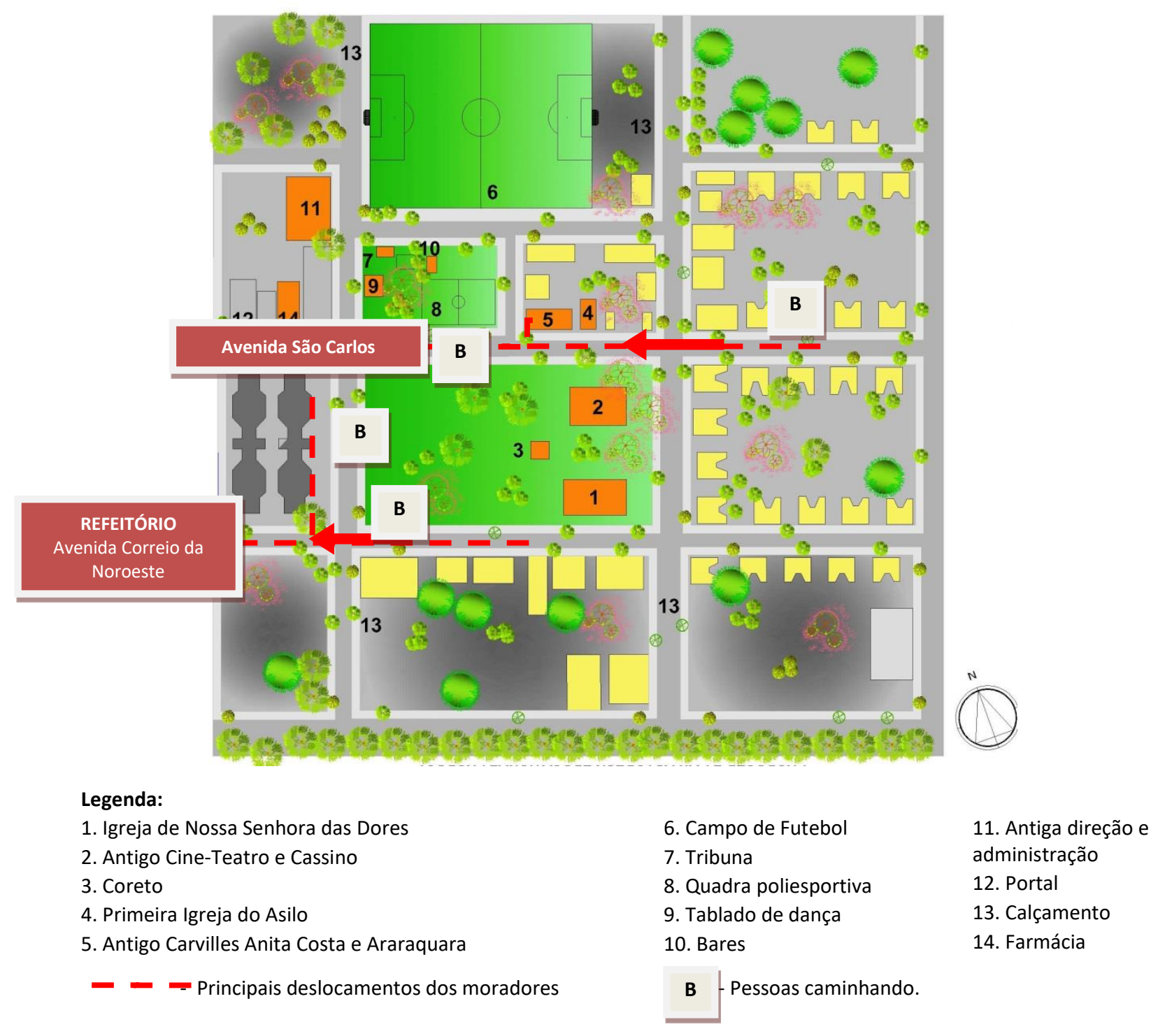

- Período da tarde e fim de tarde

11 de Junho - Por volta das 16 horas, um grupo de quatro pessoas sentaram em frente à porta de suas casas para conversar (conversa entre o grupo). Ainda por volta de $16 \mathrm{~h}$, seis moradores se sentaram na área externa do Carville e duas outras pessoas caminharam no entorno da Praça (nas vias de automóveis). Nas proximidades desse local, notou-se a presença de uma mulher com duas crianças caminhando na rua, pois as calçadas do entorno não são acessíveis e possuem barreiras físicas, como: piso inadequado, tornando o percurso perigoso (figura 9). 


\section{Revista Nacional de \\ Gerenciamento de Cidades}

13 de Junho - Na visita das 16h30, um adulto e uma criança brincavam na quadra poliesportiva e um grupo de 3 pessoas estavam na Lojinha de artesanato local. Outras pessoas se deslocavam no sentido do Carville e ali, se sentaram nos degraus de frente da edificação e mantiveram uma conversa (figura 10).

14 de Junho - No final da tarde, por volta das 17h, um adulto e duas crianças brincavam de bola na quadra poliesportiva, e bem próximo a esse espaço, um grupo de seis pessoas conversavam na lojinha de artesanato local, localizada nos antigos "bares" do ILSL. Três pessoas caminhavam próximo do Carville, sendo que uma delas, na via de automóveis. Nesse mesmo período, final de tarde, observou-se uma movimentação em frente ao Carville. Três pessoas conversavam em frente ao edifício e uma pessoa entrou no edifício (figura 11). A concentração de usuários é maior na área do Carville, pois o local abriga moradores ex-pacientes, e também serve de alojamento para pacientes atuais que residem muito longe e que vem ao ILSL para consultas e exames. 


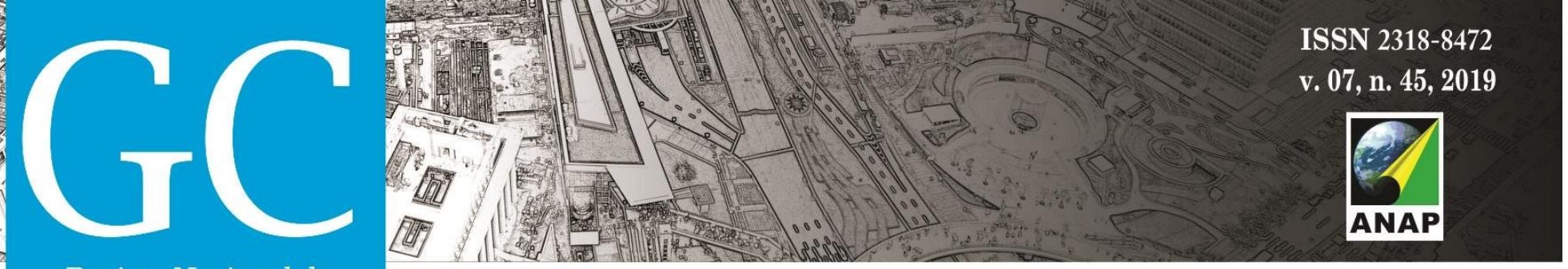

Revista Nacional de

Gerenciamento de Cidades

Figura 9 - Mapa comportamental da área tombada do Asilo Aimorés, do dia 11 de junho, período tarde e fim de tarde, sem escala.

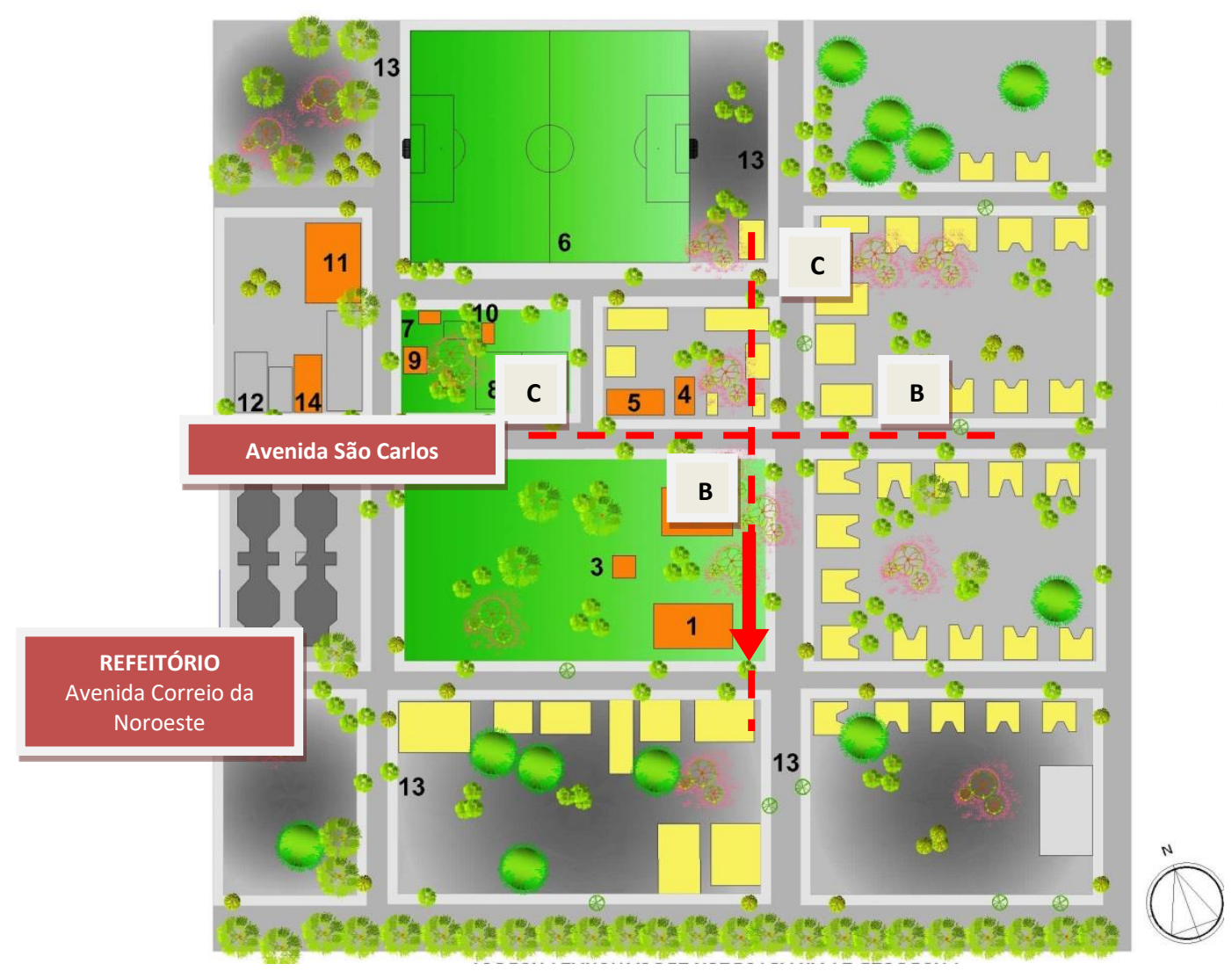

\section{Legenda:}

1. Igreja de Nossa Senhora das Dores

2. Antigo Cine-Teatro e Cassino

3. Coreto

4. Primeira Igreja do Asilo

5. Antigo Carvilles Anita Costa e Araraquara

- Principais deslocamentos dos moradores
6. Campo de Futebol 7. Tribuna

8. Quadra poliesportiva

9. Tablado de dança

10. Bares
11. Antiga direção e administração

12. Portal

13. Calçamento

14. Farmácia

\begin{tabular}{c|l} 
B & Pessoas caminhando \\
\cline { 1 - 1 } C & Pessoas sentadas \\
\hline
\end{tabular}




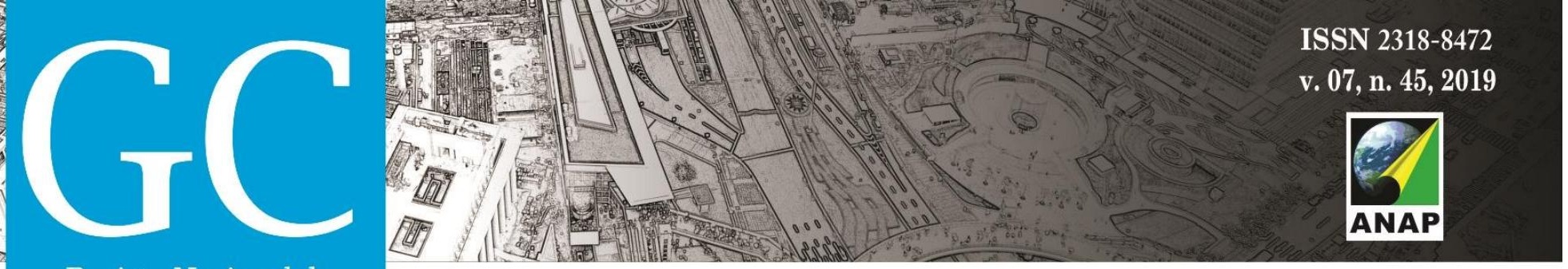

Revista Nacional de

Gerenciamento de Cidades

Figura 10 - Mapa comportamental da área tombada do Asilo Aimorés, do dia 13 de junho, período tarde e fim de tarde, sem escala.

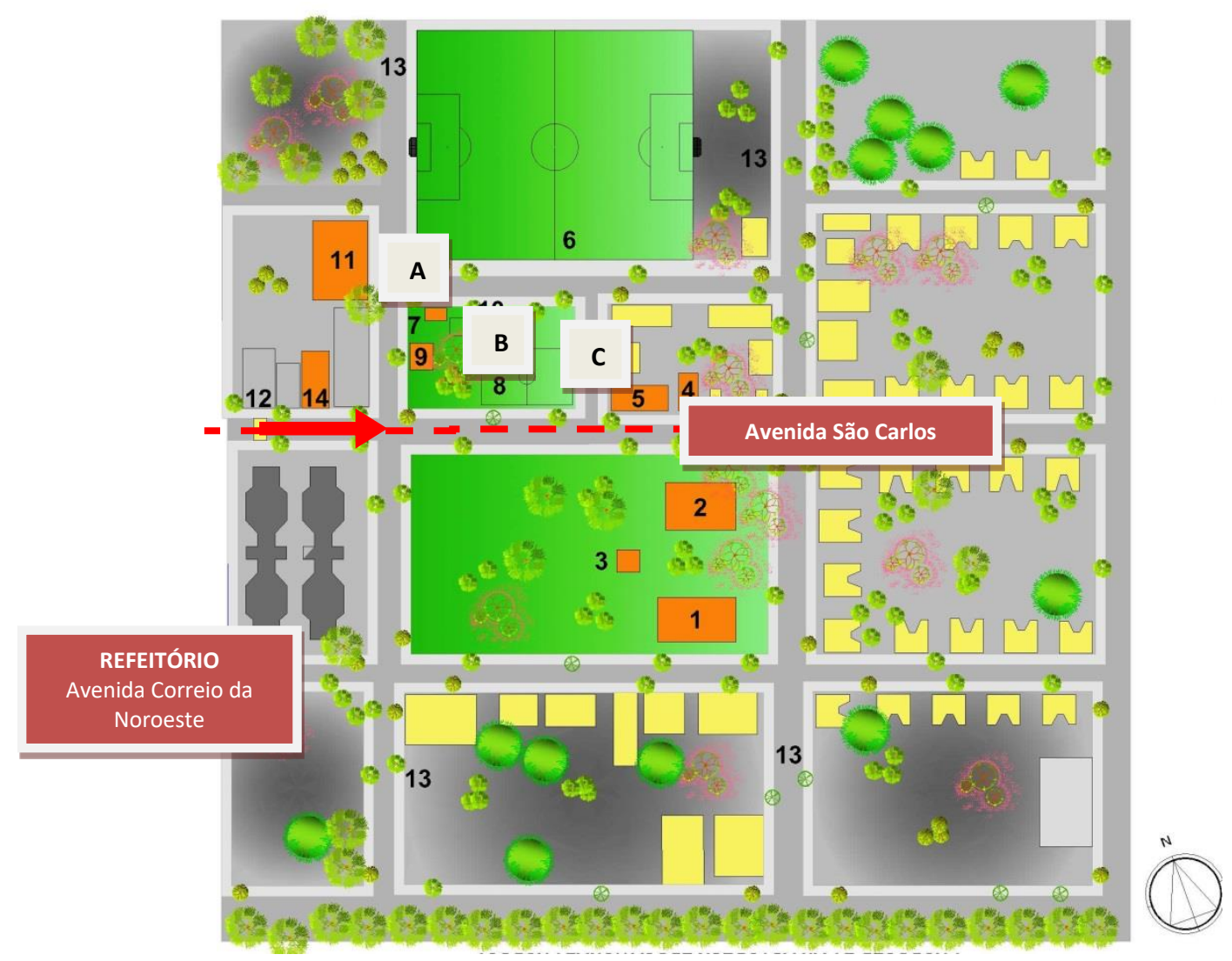

\section{Legenda:}

1. Igreja de Nossa Senhora das Dores

2. Antigo Cine-Teatro e Cassino

3. Coreto

4. Primeira Igreja do Asilo

5. Antigo Carvilles Anita Costa e Araraquara

- Principais deslocamentos dos moradores
6. Campo de Futebol

7. Tribuna

8. Quadra poliesportiva

9. Tablado de dança

10. Bares
11. Antiga direção e administração

12. Portal

13. Calçamento

14. Farmácia

\footnotetext{
A - Pessoas paradas à pé.

B Pessoas caminhando

C Pessoas sentadas
} 


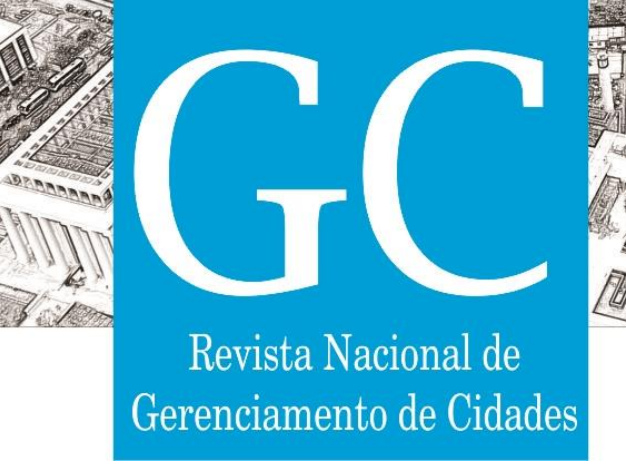

Figura 11 - Mapa comportamental da área tombada do Asilo Aimorés, do dia 14 de junho, período tarde e fim de tarde, sem escala.

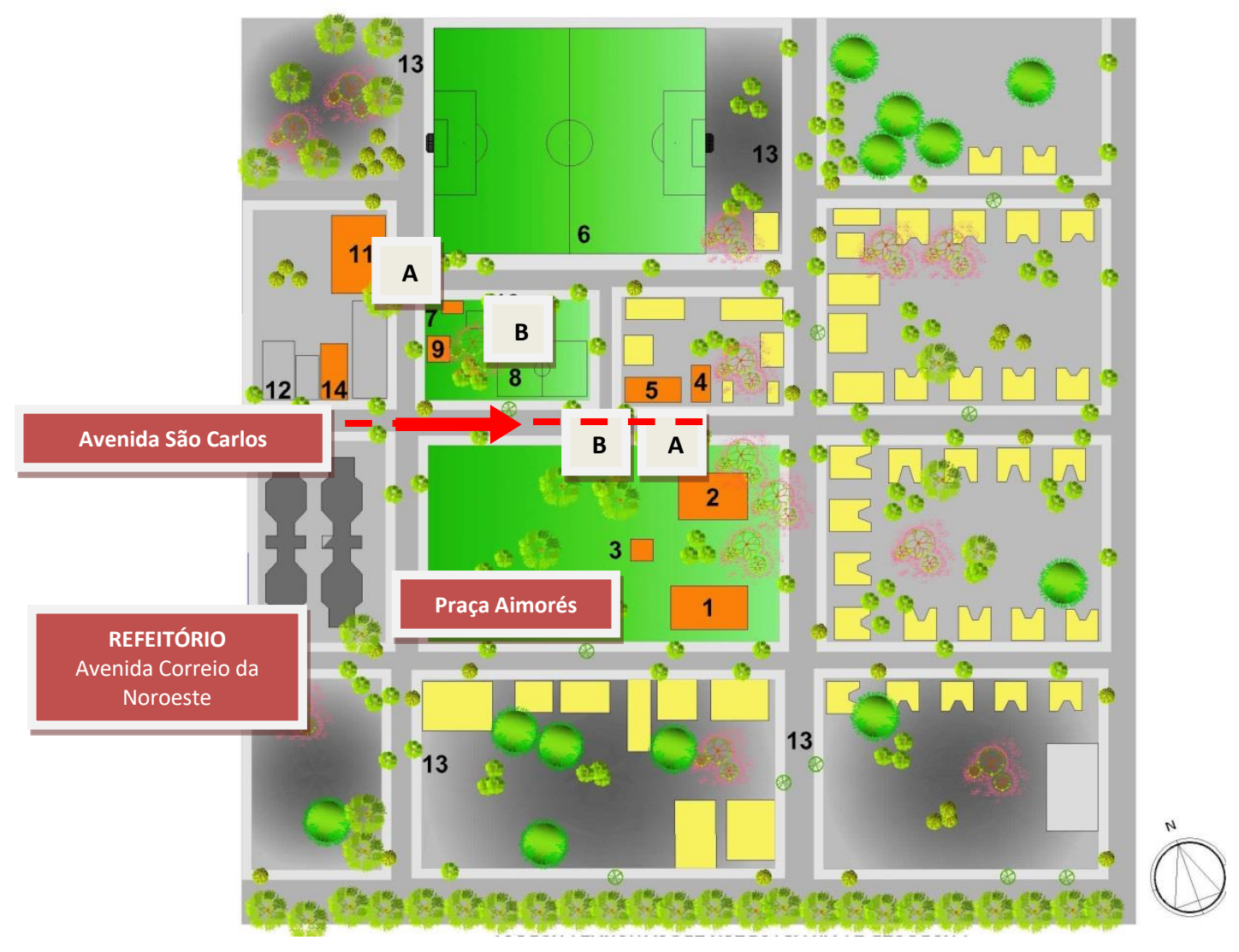

\section{Legenda:}
1. Igreja de Nossa Senhora das Dores
6. Campo de Futebol
2. Antigo Cine-Teatro e Cassino
7. Tribuna
3. Coreto
8. Quadra poliesportiva
4. Primeira Igreja do Asilo
9. Tablado de dança
10. Bares
5. Antigo Carvilles Anita Costa e Araraquara
\begin{tabular}{c|l} 
A & Pessoas paradas à pé. \\
\cline { 1 - 2 } B & Pessoas caminhando
\end{tabular}
- - Principais deslocamentos dos moradores

11. Antiga direção e

administração

12. Portal

13. Calçamento

14. Farmácia

Em síntese, a aplicação do Mapa Comportamenta, ,evelou que no período da manhã os locais mais frequentados na área tombada são: Praça Aimorés e entorno. No período do início da tarde os moradores utilizam o local como ponto de encontro para irem ao refeitório. E no fim de tarde, além da Praça Aimorés, o outro local mais frequentado é o Carville (figura 11,05).

Complementarmente observou-se que a necessidade do local ser acessível, pois muitos moradores utilizam a rua para seus deslocamentos, o que contribui para a insegurança desses pedestres. As observações ainda mostraram que o local proporciona grande interação entre os moradores, e incentiva a integração social entre os moradores. 


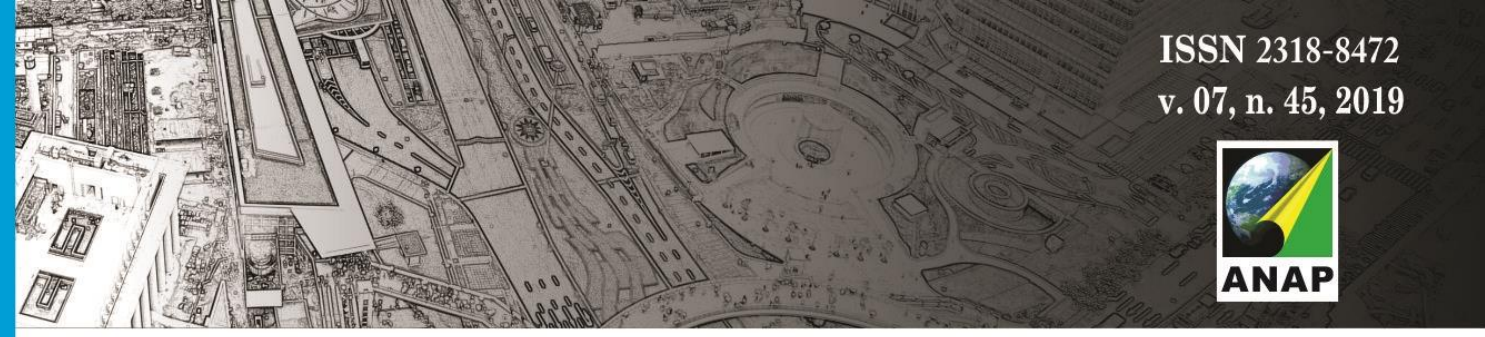

Revista Nacional de

Gerenciamento de Cidades

Observou-se que uma loja de artesanato localizada próxima a praça central é um ponto de atração dos moradores do local. Uma moradora ex-paciente, é responsável por administrar esse espaço de comércio local. São comercializadas algumas peças de artesanato confeccionadas por moradores e pacientes da Geriatria e outras são compradas para revenda.

As observações mostraram que a apropriação da área tombada, é maior no entorno da Praça Aimorés, tanto por haver vegetação de grande porte com copa fechada, que permite a permanência prolongada dos moradores no local, quanto por ser um percurso até o refeitório, que os moradores percorrem três vezes ao dia, e por ser rota de acesso aos cursos oferecidos mensalmente (no antigo Cine Teatro- Cassino) mencionado na aplicação do walkthrough. A partir dessas observações pôde-se determinar a rota acessível para ser analisada na aplicação da auditoria técnica.

\section{CONSIDERAÇÕES FINAIS}

Este artigo esse artigo apresentou o resultado de duas técnicas de observação (passeio guiado e mapa comportamental) para avaliar a qualidade espacial da área tombada do asilo-colônia Aimorés, localizado na cidade de Bauru (SP).

A partir da aplicação da técnica Passeio Guiado (Walkthrough) pode-se identificar que os principais problemas que afetam a qualidade espacial na área tombada do asilo Aimorés refere-se: ausência de calçadas no limite da área tombada; má condição de manutenção do piso em diversas quadras; presença de vegetação inadequada - na calçada ou no interior da praça; estado de conservação e tipo de piso do sistema viário local, onde na maioria das ruas, é de paralelepípedo, comprometendo o deslocamento de pedestres na travessia, pois quando molhado, torna-se escorregadio; estado de conservação da calçada, pois este encontra-se na grande maioria do trajeto, danificado ou esburacado; em alguns pontos, não há piso na calçada, sendo encontrado de cimento ou inexistente.

Em relação a aplicação do Mapa comportamental, os resultados mostram quais são os principais deslocamentos e as principais atividades realizadas pelos moradores na área tombada. Dos elementos identificados destacam-se: utilização do sistema viário para os deslocamentos, pois o piso da calçada não oferece segurança e conforto para os pedestres; a praça central (Aimorés) é um ponto de atração dos moradores, pois seu espaço proporciona momentos de convício social, em contrapartida, no entanto, não são todos os moradores que usufruem desse espaço, em função da falta de manutenção; alguns locais não são utilizados pelos moradores, pois não oferecem qualquer atividade que possa estimulá-lo ao uso do espaço. 


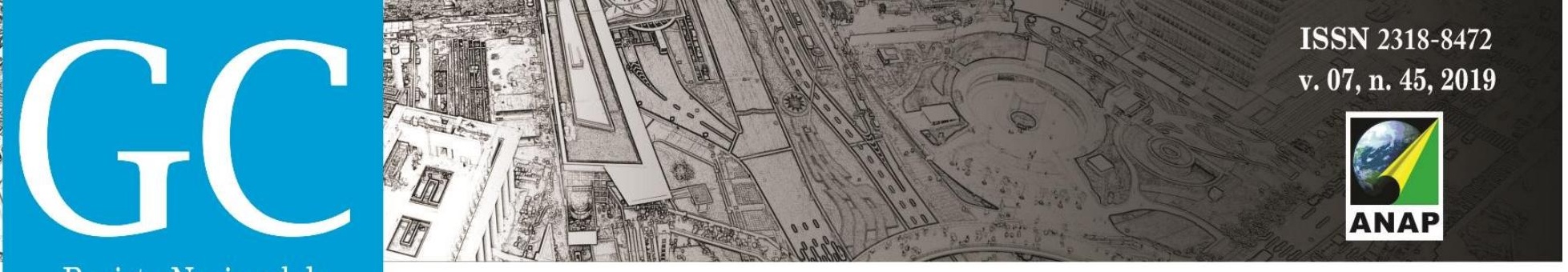

Revista Nacional de

Gerenciamento de Cidades

Diante desses resultados, pode-se afirmar que a utilização das duas técnicas foi essencial para entender, a partir de uma visão técnica, como a qualidade espacial pode interferir no uso do espaço. A partir dos resultados obtidos, os gestores da área podem intervir a partir de ações mais imediatistas ou a longo prazo, para melhorar a qualidade espacial desse local.

\section{AGRADECIMENTOS}

Os autores agradecem ao Instituto Lauro de Souza Lima e demais pessoas envolvidas por disponibilizar materiais e conceder autorização para o desenvolvimento desta pesquisa.

\section{REFERENCIAS BIBLIOGRÁFICAS}

COSTA, Ana Paula Silva. ASILOS COLÔNIAS PAULISTAS: Análise de um modelo espacial de confinamento. Anais... Seminário Internacional de Arquitetura, Tecnologia e Projeto. 2014.

CUNHA, Marcella Viana Portela de Oliveira; GOMES, Emmily Gersica Santos; FERNANDES, Júlio César Félix de Alencar. A relação entre o ambiente e o usuário - O Mapa Comportamental como instrumento de definição de rota acessível. Eneac, Recife. 2016

CUNHA, Marcella Viana Portela de Oliveira; MATIAS, Emanoella Bella Sarmento Salgueiro Eliziário; COSTA, Angelina Dias Leão. A relação entre o ambiente e o usuário idoso - $O$ Mapa Comportamental como instrumento de avaliação. XIV ENTAC - Encontro Nacional de Tecnologia do Ambiente Construído - Juiz de Fora, 2012

GERENTE, M.M. Introduzindo diretrizes de projeto para acessibilidade em sítios históricos a partir do estudo de São Francisco do Sul. Dissertação (Mestrado) Programa de Pós-graduação em Arquitetura e Urbanismo. Universidade Federal de Santa Catarina - Centro de Tecnologia, Florianópolis. 2005.

LIMA, Rossana B. F.; GUERRA, Maria Eliza A. Avaliando a relação usuário-ambiente: um estudo no parque infantil da praça Sérgio Pacheco, Uberlândia - MG. Revista Projetar. Projeto e Percepção do Ambiente v.2, n.1, 2017

MAGAGNIN, Renata Cardoso; MOLLES, Beatriz Rodrigues. Acessibilidade espacial no centro histórico de Poços de Caldas (Brasil). In: Anais... Rehabend 2016. Burgos, Spain. 2016 Cód. 5.4.03

MEDEIROS, Haendel Lopes Virgulino; MATIAS, Emanoella Bella Sarmento e COSTA, Angelina Dias Leão. Resgatando a habitualidade local: Inserção de rota acessível no centro histórico de João Pessoa -PB. Anais... VI Encontro Nacional de Ergonomia do Ambiente Construído, Recife 2016

PAIVA, Ellayne Kelly Gama. Acessibilidade e preservação em sítios históricos: 0 caso de São Luis do Maranhão. Dissertação (Mestrado). Programa de Pós-Graduação em Arquitetura e Urbanismo. Universidade de Brasília. 2009. 


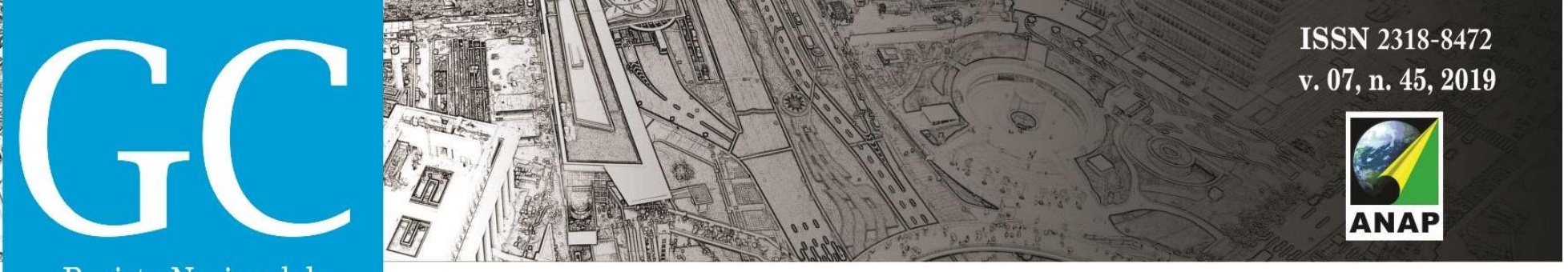

Revista Nacional de

Gerenciamento de Cidades

RHEINGANTZ, Paulo. Afonso; AZEVEDO, Giselle Arteiro; BRASILEIRO, Alice; ALCANTARA, Denise de; QUEIROZ, Mônica. Observando a Qualidade do Lugar- Procedimentos para a Avaliação Pós-ocupação.

RIBEIRO, Gabriela Sousa. Proposta de procedimentos metodológicos para avaliação da acessibilidade física em sítios históricos urbanos. Dissertação (Mestrado). Programa de Pós-Graduação em Design. Universidade Federal de Pernambuco. Recife, 2008.

RIBEIRO, G. S.; MARTINS, L. B.; MONTEIRO, C. M. G. O desafio da acessibilidade física diante da sacralização do patrimônio histórico e cultural. Cadernos PROARQ no 19. Rio de Janeiro, p. 131 a 151, dezembro de 2012.

SOUZA, Sandro Ferreira de; TIBÚRCIO, Túlio Márcio de Salles. O uso do mapa comportamental na identificação de idosos. IV Simpósio Brasileiro de Qualidade do Projeto no Ambiente Construído. 2015 